\title{
Taming the Situationist Beast
}

\author{
Lucian Leahu \\ Computer Science Dept. \\ Cornell University \\ Ithaca, NY, USA \\ lleahu@cs.cornell.edu
}

\author{
Jenn Thom-Santelli \\ $\mathrm{HCl}$ Group \\ Cornell University \\ Ithaca, NY, USA \\ jt17@cornell.edu
}

\author{
Claudia Pederson \\ History of Art \\ Cornell University \\ Ithaca, NY, USA \\ ccp9@cornell.edu
}

\author{
Phoebe Sengers \\ Information Science and STS \\ Cornell University \\ Ithaca, NY, USA \\ sengers@cs.cornell.edu
}

\begin{abstract}
The interplay between arts and HCI has become increasingly commonplace in the past years, offering new opportunities for approaching interaction, but also raising challenges in integrating methods and insights from across a great disciplinary divide. In this paper, we examine the ways Situationist art practice has been used as an inspiration for HCI design. We argue that methods from Situationist art practice have often been picked up without regard for their underlying sensibility: reflection and improvisation in an activist socio-political context. We describe an experiment in incorporating Situationist sensibility in design and use it to elucidate the challenges that face HCI in truly integrating the arts.
\end{abstract}

\section{Categories and Subject Descriptors}

H.5.m. Information Interfaces and Presentation (e.g., HCI): Miscellaneous; K.4.2. Computers and Society: Miscellaneous.

\section{General Terms}

Human Factors.

\section{Keywords}

Situationism, art, reflective HCI, methodology.

\section{INTRODUCTION}

HCI has a long history of drawing from a wide variety of disciplines to understand and design for the site of interaction, ranging from engineering disciplines, such as computer science, to social science fields, such as cognitive psychology. More recently, HCI has begun to draw from the humanities and arts as well for inspiration; these areas have become particularly pertinent with growing interest in understanding and designing for the complexity of human experience in interaction, such as its aesthetic and emotional dimensions (e.g. [4][18][19][21][22]). In the process, challenges can arise from the mismatch between theories, methodologies, and conceptualization in these new

Permission to make digital or hard copies of all or part of this work for personal or classroom use is granted without fee provided that copies are not made or distributed for profit or commercial advantage and that copies bear this notice and the full citation on the first page. To copy otherwise, or republish, to post on servers or to redistribute to lists, requires prior specific permission and/or a fee.

Conference'04, Month 1-2, 2004, City, State, Country.

Copyright 2004 ACM 1-58113-000-0/00/0004 ...\$5.00. disciplines and those already at play in HCI (e.g. [5][8]).

A major issue that arises in such appropriations is a mismatch in the understanding of 'method' between HCI and these other disciplines. As a result, methods may be appropriated as relatively straightforward recipes for action, without regard to their richness or use in their home discipline. So, for example, Dourish has critiqued the uptake of ethnographic practice in HCI, arguing that theoretically grounded analysis which takes into account the analytic stance of the ethnographer has been reduced to a simple method by which any person can extract objective meaning from a cultural situation [8]. Boehner and colleagues report similar issues in the uptake of the cultural probes [5]; what was intended as a subversive, arts-inspired approach questioning the basic assumptions of HCI methodology has become a relatively standardized and unproblematic method (see also [12]).

In this paper, we look at issues of methodology that arise in the uptake of the arts in HCI. Specifically, we look at the relatively popular use of Situationism as an inspiration for alternative forms of HCI design. We will argue that, as with ethnography and the art-design approach of the probes, Situationism has frequently been adopted as a set of methods irrespective of its original motivation and context of use. We demonstrate through a case study of the design and evaluation of an alternative system inspired by Situationism what it might take to draw seriously on the arts in HCI. Finally, we use this opportunity to discus the implications of our findings and to situate our analysis within a larger trend of appropriations in HCI.

\section{BACKGROUND}

Situationist art practice developed over a period of sixteen years from 1957 to 1973. The Situationists deemed the present the age of the "spectacle," a concept that evokes connotations with mainstream theater, a display, a show, or any type of performance that positions audiences in the role of passive witnesses of onstage dynamics. According to the Situationists, consumer society positions people in similar passive roles. The role of the consumer, as the Situationists saw it, limits participation to a set of predetermined choices that may satisfy material well-being, yet impede peoples' agency in shaping the underlying structures of society. The spectacle of material abundance conceals the alienation from one's creativity and societal environment. The Situationists set out to devise 'situations', or experimental practices aimed at raising awareness vis-à-vis the general conditions that prevail in a place or society. Situationism proposed to affect a shift in public awareness towards a participatory model that would challenge materialism as the basis 
for negotiating human relations. It is important to note that the devised situations went beyond performance spaces, attempting to transform entire neighborhoods or cities, i.e. they had a central activist component.

The Situationists developed tactics to support questioning of the consumer spectacle, such as the dérive, a series of random drifting walks through the physical space of the city [17]. The dérive was taken up by the Situationists as a strategy for exploring psychogeography, "the study of the precise laws and specific effects of the geographical environment, consciously organized or not, on the emotions and behavior of individuals" [7]. Through drifting, participants approached the city outside of a goaloriented frame, aiming to experience new social, political, and historical ambiences or moods in traversing the physical space. The dérive was conceived as part of a larger set of generative strategies geared towards the creation of situations that would reveal and disrupt the conditions of the 'spectacle.' One of the most well known results of the Situationist dérive is the Naked City (Figure 1), a map constructed by Guy Debord, the leader of the Situationist International. This map consists of 19 cut-out sections of a map of Paris, corresponding to neighborhoods that the Situationists felt still retained a communal life unspoiled by the forces of capitalism and bureaucracy. The map was meant to describe the fragmentation of Parisian urban existence that followed the displacement of the poor and middle class. The arrows connecting the neighborhoods suggest connections between them, but also emphasize the gaps between the neighborhoods to provoke interpretations and to open up a space for multiple narratives that implicate a combination of particular social, political, and historical forces shaping the landscape.

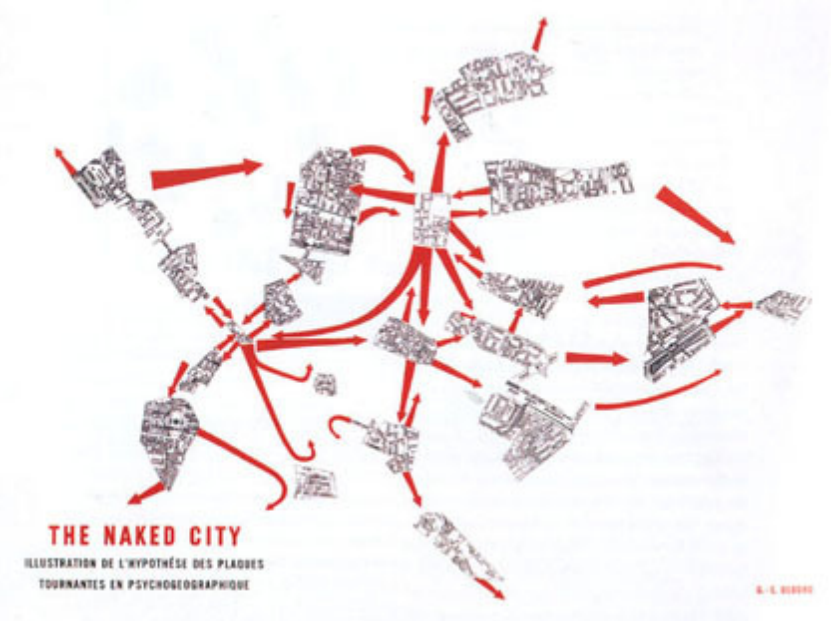

Figure 1: The Naked City

Another tactic employed by the Situationists that received significant attention in HCI is the detournement, a form of subversion in which media elements are rearranged to question their given meaning, in order to intervene in the status-quo. Key to detournement is the re-appropriation of tools and ideas that the established order deploys for its ideological ends, in order to suggest new, alternative meanings and to support critical reflection. A popular example is the work of the activist group Adbusters [1]: one instance is the subversion of Nike adverts (Figure 2). In this case, the image in the original ad is altered in order to draw attention to Nike's policy of shifting their production base to cheap labor cost third world 'Free trade Zones'. The modified ad provides the cost and place of production, as well as the brand name and the in store selling price.

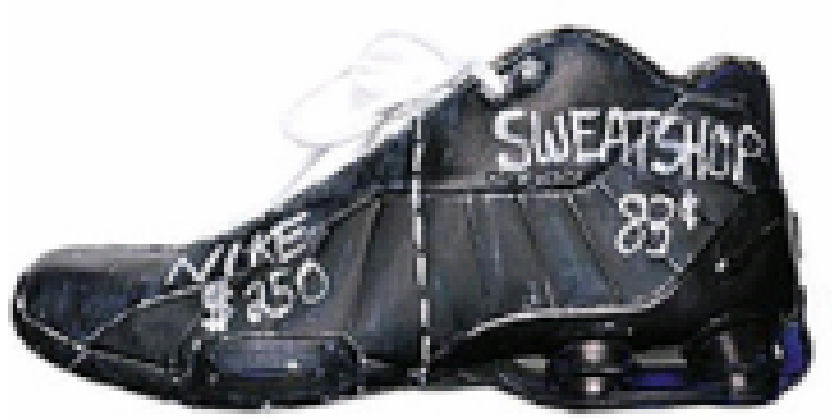

Figure 2: Detournement of Nike advertising

\subsection{Uptake of Situationism in HCI}

Situationism has gained popularity in the HCI community in recent years [6][9][10][13][16][20], with contemporary technology designers who sympathize with the liberal outlook of modernist counter culture seeking to engage its artistic legacy in conceiving and building machines. One of the primary ways in which Situationism has been taken up is by adopting the methods of the Situationists. Specifically, in HCI, Situationism is often cited as an inspiration when the detournement and the dérive are adopted as methods for building systems. In this section, we exemplify the way our community adopted and adapted these two Situationist tactics, by contrasting them to the artistic or activist use of the same tactics.

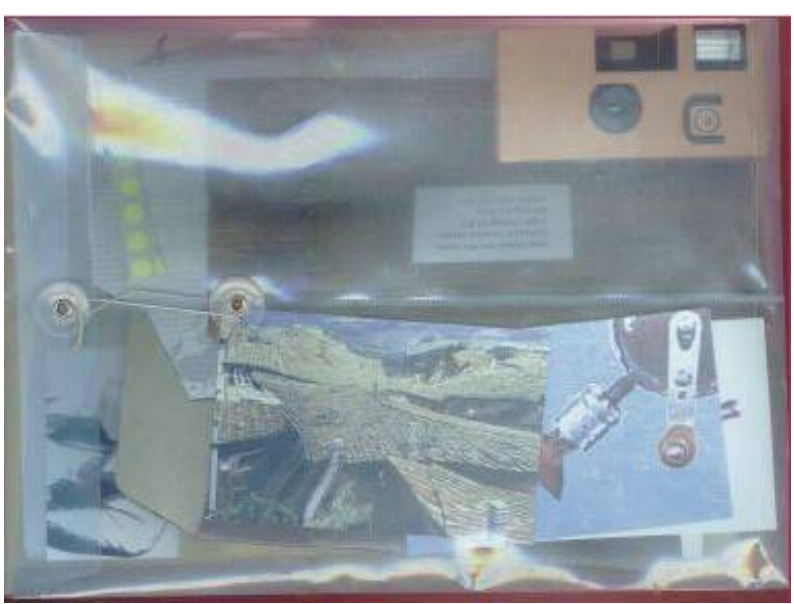

Figure 3: Probes use detournement as a way to stimulate reinterpretation of user lives and of HCI methodology [14]

Perhaps the most prominent example of the uptake of Situationism in HCI is the cultural probe [13] [14]. Probes draw on detournement to question the basic assumptions of HCI methodology. For example, one of the traditional roles ascribed to designers is that of the expert that diagnoses user needs. The cultural probes were intended to question such roles as they were "designed to disrupt expectations about user research and allow 
new possibilities to emerge." [15] (p. 23). While the original probes subvert the status quo, in order to convey a different message, their broader uptake in HCI has often lost this subversive sense [5] and as a consequence become unrecognizable as a form of Situationist practice.

In HCI, an example of the use of dérive is in Sonic City [16]: Sonic City is a pervasive system that samples music by sensing variables, such as ambient light and temperature, in the urban space. The system encourages users to interface with the city through continuous movement by linking changes in the music to those in the environment. The similarities with the Situationist dérive concern only the physical aspects of the dérive: the pedestrian experience through the physical space of the city. However, the purpose of the drifts are very different: in Sonic City the users explore the city, seeking to link changes in the music to changes in the environment, while, for example, Debord's drifts in Paris resulted in Naked City, a map that visualizes a city fragmented by multiple restructurings caused by the capitalist society.

Similar patterns of adaptation arise in other projects that draw on Situationist art practice. As we will describe shortly, in being adapted to use in HCI, these projects often pick up on the easilyrecognizable external forms of Situationist practice, but without recognizing or incorporating the motivations and intentions that underlie it. The forms of Situationism become decontextualized, reified and reproduced while the spirit that animates them is lost. We particularly note the two following problems.

\subsection{Reinforcing Rather Than Questioning the Spectacle}

Instead of questioning the implications of consumer culture (i.e. the "spectacle"), these projects often play into values that characterize the capitalist modes of production Situationists sought to question. For example, FIASCO [6] is described as a location-enabled urban game where "the goal...is to dominate territory on the map (p. 330)." The Situationists, however, did not condone the colonization of urban space but rather actively questioned the legacy of ownership of space. As another example, Instant Archaeologies links an art gallery with urban space through projections of a dérive enacted through participants' cellular phones. In contrast, the Situationists saw art galleries as problematic spaces, authoritative sites that supported the commercialization of art practice by warranting the artistic value of objects [10]. This was part of a larger critique in which Situationists denounced the artificial separation between art and life. More generally, Situationism is drawn on in projects whose ultimate end-goal is to create new commercial products - a purpose which is fully opposed to the Situationist aesthetic.

\subsection{Reifying Tactics as Methods}

The decontextualization of Situationist tactics, such as the dérive and detournement, contributes to their codification as method. To understand what is at stake in this shift, it is important to understand the difference between a tactic in arts practice and a method as used in HCI. A tactic is a strategy employed for critical means, which may be continually changed according to the context. Far from a recipe, it requires reflection on its use and is altered and developed to fit the circumstances on the ground and with the goal of promoting the original critical intent. A method as conceived in HCI, on the other hand, is much more stable. It is based in the notion of codifying practice to support broad use, and promotes stabilization and generalizability. Although all methods require reflection to apply in a situated context, value in HCI is often found in methods that require less reflection and tailoring and that are more easily transferable between projects and persons. To put it perhaps too broadly, methods are oriented to establishing means, while tactics are oriented to achieving ends.

In the uptake of Situationist tactics in HCI, they generally become codified as methods, and, in the process, lose the link to their original intent. For example, in Sonic City the users are encouraged to interface with the city through continuous movement by linking changes in the music to those in the environment. The method used in this example is the dérive, but there is no recognition of the political implications that drive the design and use of the dérive in Situationist practice. Instead, mobility is used only as a method, not as a tactic.

\subsection{Rethinking Situationist Uptake}

The designers of the above cited HCI projects share the Situationist goal of building technologies that support users in reflecting on physical or conceptual spaces and their interaction with these spaces. It is in part for this reason that they draw on oppositional and activist culture. At the same time, the projects tend to enact a split between the techniques of Situationism and its broader goals, drawing on the first while leaving the second behind. This split is not inherently problematic. To slavishly copy Situationism as a cultural form is both unnecessary in new contexts and contradictory to the tenets of Situationism, which would encourage reflection on all forms of reification, including that of Situationism itself.

What is problematic about this split is the fact that it is largely undiscussed. By drawing on the 'methods' of Situationism without reference to their intent, these projects separate easily reproducible forms and procedures from the complexity of the activist context that gives them meaning. By not acknowledging this separation, the motivation behind the separation is not clear, and its consequences are unexamined. Such work leaves behind the possibility of a deep engagement with art practice in favor of an instrumentalization of its methods.

What would happen if HCI were to take Situationism seriously on its own terms; not as a source of methods, but as a sensibility for approaching design? We explore some answers in the remainder of this paper by describing the conceptualization, execution, and results of an experiment in taking both Situationist goals and tactics seriously in technology design.

\section{THE SITUATIONIST AGENT}

Drawing on the Situationist goal of questioning the Spectacle, our intent was to build a critically-inspired system that encourages reflection on the everyday use of computers as a tool. The Situationist Agent (Figure 4), or SIA for short, is a software application that crawls the web, starting at one of several prespecified websites and following links as the 'walk' progresses. The agent collects images, text and e-mail addresses that it finds on its virtual dérive. The images and text are displayed in the agent's window. The bottom part of the SIA window includes a panel that displays traces of the agent's execution such as information about the agent's whereabouts and actions. 
...rmation service relating to activism, revolt, and the dissemination of information Anarchist Black Cross

Status unknown http://burn.ucsd.edu/ mailabc_kiosk.html

Anarchist prisoner support and prison abolition network

Anarchist Communitarian Network

Status unknown http://www.anarchistcommunitarian.ne...

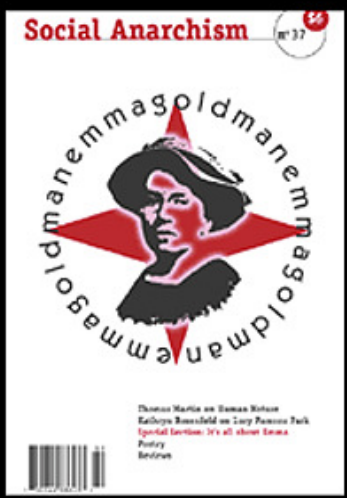

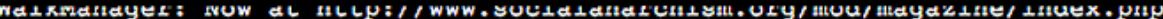

WalkManager: Bxtracted 24 links, 4 images, 0 emails.

DataAnalyzer: extracting a piece of text

WalkManager: Sleeping for 1 minutes...

WalkManager: Time left $=61$

WalkManager: Now at http://www.socialanarchism.org/mod/links/index.php

WalkManager: Extracted 14 links, 2 images, 0 emails.

DataAnalyzer: extracting an image

Figure 4: The Situationist Agent

In the following we explain how the SIA engages with Situationist art practice, speaking to its original tactical intent. The separation of the design decisions with respect to the two identified problematic aspects is artificial, as some of the design features support both arguments.

\subsection{Questioning the Spectacle}

As mentioned before, the SIA's goal was to encourage reflection. As such, the purpose of our experiment was not to design an endproduct in itself (i.e. the SIA), but rather to set up a reflective experience facilitated by the agent; in Situationist jargon the SIA involves both users and designers in a 'situation.'

In order to stage this 'situation,' we use a detournement: the appropriation of computers for non-practical purposes. This is in itself not novel as personal computers are often used for both work and entertainment purposes. The SIA is, however, not designed to entertain the user per se. As the user has no control over the activity of the agent, the design of SIA is oriented around questions about the role of technology and the illusion of choice in today's society.

Another design feature deployed to question the spectacle is the collage of images and text collected by the agent on its dérive. As these images and snippets of text are truncated and presented out of context, their original meaning is being subverted. The new meaning of the collages is purposely left ambiguous to allow the users to engage with the agent in an unconstrained way and to develop their own reflections [11].

Apart from images and text, the SIA also used the dérive to engage in new conversations by way of e-mail: virtual graffiti was left behind, in the form of e-mails sent by the agent to the addresses discovered on the visited websites (Figure 2). The SIA graffiti carries the intention to create situations of communal expression, provoking other online users to enter into dialogue: a wiki was set up for the SIA, explaining the project, offering the visitors the chance to submit comments and to download the agent. 


\subsection{Keeping Tactical Intent}

In the design of the SIA we were interested in adapting the main Situationist tactics (dérive and detournement) to our needs. We attempted to go beyond the easily reproducible 'form' of these approaches and to stay in line with the Situationist 'spirit.'

On its virtual drift the agent is directed by textual rules towards sites that contain words and images connected to particular ideologies associated with Situationism. The intended effect is to direct users' reflection to the ideologies underlying the spectacle of the virtual. In other words, the dérive goes beyond simply traversing a space, it is intended to critically engage with this space and its intrinsic meaning. The SIA's drift has the form of a Situationist dérive as well as a tightly coupled reflective component.

The uptake of Situationist ideas in our project is also ironic towards Situationism itself. In keeping with the idea of a subversive art practice, the SIA subverts the Situationist practice using a Situationist tactic. Central to the design of our agent is the detournement of the Situationist persona: the SIA is coded to 'behave' as a quintessential Situationist. The SIA is equipped with a knowledge of French, a penchant for using lots of big scholarly words, to refer to boredom ("there is nothing they won't do to raise the standard of boredom."), poverty ("of the university, of art") and pleasure, to be familiar with Dada and Surrealism, and to use Marxist jargon.

\subsection{Questioning Positivist Evaluation}

Like [18], it is not our intention to force HCI-influenced evaluative techniques on interactive arts-inspired systems. Instead, we sought to bring attention to the value of focusing on the subjective and idiosyncratic processes of meaning making because the SIA design is itself intended to raise questions about the cultural values surrounding technology. This differs from typical understandings of design in HCI, where a design is typically thought of as successful only if the perspectives embodied in the design play out in practice. Art objects, in contrast, are a form of expression, and hence may be considered interesting objects-to-think-with even if they are not accessible to 'average' users. At the same time, within Situationist-inspired practice, evaluation can be understood as an opportunity to create another 'situation,' one which can stimulate reflection by users and designers alike.

Again, similar to [[18], we wanted to find a way to observe how interaction and meaning-making would emerge with our system in use. Therefore, we wanted to find a compatible approach that would allow us to get a better idea of whether interaction design issues would interfere with this process. From a standard HCI perspective, our main goal in this evaluation was to assess the extent to which we were able to spur critical reflection about consumerist ideals of technology use, especially the widespread cultural notion of the computer as a tool for productivity and efficiency.

However, by decoupling evaluation from our design rationale (to examine the decontextualized uptake of Situationism) by uncritically adapting traditional usability methods, we run the risk of reifying the positivist tradition of evaluation through hypothesis testing and adherence to the scientific method as the only true form of knowledge creation. To that end, we also wanted to reflect on these foundational assumptions that lie within the practices of HCI evaluation. Rather than retreating to familiar tropes or thoughtless uptake of measurement techniques, we strove to incorporate 'situations' into our evaluation by defamiliarizing its form but at the same time, allow those who interacted with SIA to easily express and reflect on the experience.

We focused first on participant selection as an aspect of evaluation to be defamiliarized. Instead of employing sampling procedures valuing generalizability in the experimental sense, we wanted to encourage the highly personal interpretations that we hoped might develop while the participants interacted with the SIA. As a result, we decided to use the metaphor of gift-giving in the evaluation: i.e., to give the system as a gift to people with whom we had an existing relationship. Focusing on familiars was a deliberate choice so that we draw awareness to the subjectivity inherent in all manner of evaluation. We, however, leveraged this subjectivity to draw out the intricacies of the messy relationships between designer and user by asking 8 of our friends to install an unknown system on their personal computers for one week. By choosing to use friends as giftees, we hoped that our shared historical experiences would help us elicit richer narratives that might be created in the interpretation of the SIA. At the same time, we were aware of the danger that our giftees might not feel as free to express negative feedback.

In keeping with our design goal to preserve tactical intent, we played in the evaluation with the idea that the SIA had an autonomous identity as a Situationist. During the week, we sent daily e-mails to the giftees from the SIA using the slogan-like language of the Situationists as a probe to encourage reflection on the content displayed during the system's dérive. To keep up the game, we created a separate e-mail account for the SIA to make it seem that our agent was solely responsible for the sending of the messages.

However, as in the case of [18], we needed to decouple whether or not the SIA provoked giftee reaction whether through 'situation' or faulty design decisions on our part. As a result, we also implemented more traditional forms of evaluation. Midweek, we sent a short open-ended e-mail questionnaire to each giftee. These differed from the previous SIA-sent e-mails as they were sent from our personal e-mail accounts and the language was of a conversational tone. At the end of the week, we conducted indepth interviews with each giftee to engage them in conversation about their experience with the SIA.

\subsubsection{Giftee experiences}

The observations gleaned from our evaluation were similar in some ways to the appreciation of art, in that aspects of our tactical approach highly resonated with some of giftees while others were indifferent to them. Three of our giftees viewed the e-mails as a provocation and at times, almost taunting, in that the SIA was exhorting them, respectively, to either do something revolutionary or that they needed to rise to the challenge of responding the SIA in a suitable way. In contrast to the midweek evaluations, which were more straightforward and sent from our personal e-mail addresses, another set of giftees found the e-mails from the SIA to be too vague. They just were not interested in responding to the SIA but felt that the response to the midweek evaluation would be useful information to the system designers. 
With respect to our main goal of assessing the occurrence of critical reflection about the spectacle of technology as tool, this was again taken up in an art-like manner in that three of our giftees (AR, CR, MF) responded strongly to the actions of the SIA. For giftees AA and CR, the SIA encouraged critical reflection regarding, the decision to trust technology even if it is unclear that the technology may be surveilling you in some way.

"The magician works by keeping your eye at what seems important but isn't, while the slight of hand occurs, unseen. I can't know that when I'm using SIA, it isn't doing something on the side, keeping me distracted... I was told SIA wouldn't collect any data, but how do I know this? Because the program is always visibly running, I can't use my computer without thinking 'What will SIA think of this?'” (Excerpt from e-mail from CR)

During the final interviews, both AA and CR expressed concern that the SIA might be doing something that they did not know about because the interface of the SIA did not allow for active interaction. The aesthetics of the SIA, especially with the code panel and terminal, led them to believe that it was unfinished and experimental in some way. However, systems with professionally designed interfaces, such as productivity software, engendered more trust for them despite the hidden nature of the inner workings of these systems because these programs offered some functionality that the SIA did not. Their experience with the SIA triggered some conscious reflection about the tradeoffs, in terms of their vigilance over securing their private data or hard drive, which these giftees have made in order to install systems on their computers that they find to be useful.

One of our giftees, MF, was especially receptive to the SIA's tactics and responded to the system in a Situationist-like manner. We had purposefully left much of the code running the program exposed in a directory that would be easily accessible to the giftee, if he or she was so motivated to look for it. MF was unhappy with the images of the spectacle that the SIA was choosing for him so he altered the parameters of the program so that the dérive would drift in a different manner.

To my mind, it felt like a bad television commercial. But since I felt a duty to watch the SIA program do its thing (I had, after all, agreed to be part of the project, which I think creates a weak duty to participate in some form or another), I decided to interact with SIA by changing the channel. I've since modified the files SIA is using to orient its crawl or walk to something more in line with my area of study. (Excerpt from e-mail sent by MF)

MF adapted our initial tactic of detournement to his own end and then challenged us during his in-depth interview on whether our system was indeed truly Situationist. He recognized the content displayed during the SIA's walk as Situationist in nature but did not believe that our conceptualization of the dérive and detournement was true to the tenets of Situationism.

The others believed it to be nice to look at but ultimately a peripheral interface that did not serve a 'real' function on their computer. The lack of input allowed by the system underscored this perception by emphasizing the difference between the SIA and the other systems on the giftees' computers.
"SIA extracts text and images from different sites but what is happening with the e-mails? Why don't I have any control? What's the point?" (E-mail response from AA )

"My feelings haven't really changed. I don't see the relevance, I don't have any control." (Last e-mail response)

Since the SIA did not seem to be functional, controllable or interactive, giftees believed that this type of art-inspired system would not necessarily hold a central position of importance, especially when they were busy with work, since the evaluation coincided with the end of the academic semester.

The suggestion that the computer's function might be expanded to include art and ambiguity was not met with great enthusiasm. AA expressed the view that his computer was not for art except for the art he could create by manipulating his digital photos. He did not think that his computer was the best way to discover new art; instead, he would go to the museum. Other giftees thought it might be possible that they would be open to the idea of a system that was not necessarily task-related but that those systems would be somewhat marginalized as something that might be for fun.

In the end, our giftees expressed some general frustration in their experiences with the SIA, mainly derived from the methods used to defamiliarize people's expectations of software as a tool. They were unhappy at times with the lack of controls in the interface and were puzzled by the seemingly random assemblage of text and images displayed by the SIA. In effect, the aspect of the 'situation' resonating most with our giftees was the absence of interaction allowed by the system, not the collage of images displayed by the SIA. From a traditional usability perspective, one could conclude that our system was flawed because user frustration was tied to the interactive choices we made as designers. However, from a Situationist point of view, we successfully created a detournement by drawing attention to the illusion of control exerted by a user over his or her personal computer.

\subsubsection{Reflection on the giftee/designer position}

Because we essentially framed our evaluation as a critique, it is necessary to reflect on our experience in light of our efforts to close the gaps between designer, evaluator and user. In the giftgiving framework, we deliberately chose people that we knew, who were our friends, to evaluate a system that we designed. Because it was a possibility that our friends would feel forced to participate or be less likely to give negative feedback, we emphasized on our consent forms, the midweek evaluation and in our face to face conversations that we were looking for their honest opinion on their experiences. We did receive a substantial amount of negative feedback so it appeared that giftees were not censoring their responses and may have been more open to sharing this with us, judging by some of the responses we received via e-mail and during the final interviews.

We also let our giftees know that they did not need to have the SIA in their foreground for the week and let them know that it was okay for them to ignore the SIA if they found that they were not interested in looking at it after a while. In a way, this strategy was fairly successful. Almost all of our giftees admitted that they were less interested in looking at the SIA after the immediate curiosity had worn off and they did not feel compelled to keep it 
running continuously. However, there was a specific type of obligation, expressed by two of the giftees, which was about the need to act as a "good" participant in the process. This suggests that we were not wholly successful in mitigating the imbalanced dynamic between evaluator and user.

\section{DISCUSSION}

Our design and evaluation of the SIA brings out a number of challenges to existing practice that are likely to come up if $\mathrm{HCI}$ seriously engages Situationism.

\subsection{Clashes in values}

The first challenge raised is a need to rethink the standards of what counts as a 'good' system or situation. During our evaluation, users expressed frustration and unhappiness with the system. By the ordinary standards of HCI, this would suggest the system was a failure; but frustration and unhappiness does not necessarily make a system a failure as a Situationist intervention. One of the most famous Situationist interventions was a hijacking of a church service by an imposter priest who gave a sermon railing against the spectacle; it is likely that many of the parishioners were at least as frustrated as our users [8]. The situation was still seen as a success because, for example, it raised broader awareness of Situationism and publically critiqued an institution otherwise seen as inviolable.

Indeed, the notion that the value of a practice, process, or outcome is defined by how broadly accessible and popular it is would be seen from a Situationist perspective as precisely the values of the spectacle. These are the values that are required to make successful consumer products which users will acquire without reflection. Situationist values instead focus on putting kinks in the works of the machines of production and consumption.

More generally, our experiences with Situationism suggest that reflective, art-inspired work is not necessarily going to be fun or popular. We cannot begin the design process with the expectation that an arts-based system will necessarily provide its users with an enjoyable experience. When art is applied as critique, the end result may be unsettling and provocative for its intended audience. During the deployment of the SIA, the critical and ideological strands of the project may have caused more frustration than reflection for a number of the users. If we apply the standards of art, the visceral reaction of frustration might be welcomed by the creators of the system. If we, as system designers, are serious about drawing from the arts as a resource, we should be prepared for users to have an unpleasant reaction.

\subsection{Questioning reification}

From a standard HCI perspective, the issues around what counts as 'good' may sound like simply an issue of different metrics of success, to which the familiar strategies of design and evaluation can be applied. The problem, however, runs deeper; it is not simply that HCI and Situationism seek different outcomes, but also that they maintain a different orientation towards outcomes in the first place. In HCI, the focus is on the creation of a final system or product, with design oriented towards the creation of that system and evaluation aiming for a binary answer of success or failure, along with a finite and definable list of generalized lessons learned. In Situationist practice, the focus changes from product to process. The goal is not to create specific products - far from it - but to create situations that inspire reflection on the consumer spectacle of society.

From a Situationist perspective, both design and evaluation shift from an outcome orientation aimed at creation of a final product, or a binary answer of success and failure, to ongoing processes of feedback and reflection for designers, users, and the broader HCI audience. In remaining true to this sensibility, then, the goal, is not to adapt existing methods to give a new yes-or-no answer, but to develop both design and evaluation as 'situations' which stimulate reflection.

This interest in process extends to the Situationist perspective on methods. Situationist tactics are not intended to be one-size-fits all recipes for cultural production, though they have often been taken up this way, not only in HCI. While in HCI, methods are often seen as recipes whose proper execution guarantees the truth and generalizability of results, in Situationist practice the reification of methods into recipes that can be applied unthinkingly is viewed with a great deal of suspicion. Rather than methods, Situationists call for the situated improvisation of tactics with an eye to achieving particular political ends. The use of detournement and the derive as methods for creating products in HCI would be unrecognizable and probably unpalatable to Situationists.

\section{IMPLICATIONS FOR HCI}

Our argument in this paper so far has been that in the interdisciplinary engagement between HCI and Situationist art practice, art practices have been taken up in ways that would make Guy Debord turn in his grave. The primary question that remains is why this should matter for HCI.

The first question we must address is whether it is wrong to use Situationist tactics as decontextualized methods in HCI, Are design projects that take Situationist tactics as methods fundamentally incorrect or flawed? The answer is clearly no. There is nothing wrong with taking inspiration from the Situationists for one's own practices in ways that diverge from their original intention. There is no need to ask an artist for permission before doing one's own research. Indeed, the very projects we critique for being insufficiently Situationist are still interesting and important contributions to HCI research. And given that the Situationists dissolved themselves when they felt that the movement had become too codified, the idea of promoting 'one best way' to engage in Situationist practice itself runs counter to Situationist sensibility.

The problems for HCI in insufficiently addressing Situationist sensibility are not rooted in any particular design project which may draw on Situationism in any way that it sees fit. Instead, they are rooted in the systematic patterns of uptake of Situationism that emerge in the field as a whole. What is striking in observing how Situationism is brought generally into HCI is that specific core aspects of Situationism - specifically, its political stance, its critical focus, and the improvisatory nature of its tactics - are systematically elided without discussion. A recognition of this elision and an open discussion in works drawing on Situationism of what is taken up, what is left behind, and why would benefit the field in the following ways.

1. Better integration of Situationism. The growing adoption of Situationism in HCI appears to be motivated, at least in part, by a genuine interest in the original arts practices. The 
adaptation of Situationist principles in ways that do not truly reflect Situationist sensibility sometimes appears to occur not from lack of interest in that sensibility but from a lack of understanding of it. By reflecting on what aspects of Situationism are frequently left out of HCI, we place researchers who are genuinely interested and motivated by Situationism in a better position to address Situationist concerns in their work.

2. Better relations with the arts. The growing interest in the arts in HCI practice stems, at least in part, from a recognition that art practice can provide us with new ways of approaching interaction that may be useful to us. Yet the current uptake of Situationism is more likely to shut down conversations with artists than to encourage them to engage with us. Alternative and subversive arts practices in particular appear to undergo a process of sanitation on entering $\mathrm{HCI}$ in ways that problematize future conversations with their originators. Thinking carefully about how to integrate arts sensibility with HCI practice would be more likely to generate opportunities for collaboration and engagement between the disciplines.

3. Opportunities for innovation. One of the major benefits of engaging with the arts, rather than disciplines more traditionally linked with $\mathrm{HCI}$, is the possibility of genuine innovation. True innovation arises precisely because the arts are in some ways a poor match with HCI practice, and we therefore have to entertain new orientations to our practices in order to build on them. If we do not reflect on these differences and challenges, we are likely to simply adapt foreign ways of thinking to business-as-usual in HCI and therefore lessen the opportunity to innovate.

But the greatest value to $\mathrm{HCI}$ as a field in recognizing and discussing the systematic elisions in the take-up of Situationism is to provide us with a new lens to think through why we do things the way we do and whether we should consider alternatives. So, for example, the recognition that reified methods, while natural to us, are not the modus operandi in Situationism, raises questions about why reified methods are so valued in HCI in the first place and whether it might not be useful for us, too, to take a more improvisational approach.

\section{CONCLUSION: TAMING THE POLITICAL BEAST}

In this paper, we have argued that, in the process of reifying Situationist tactics, the political and critical aspects that make these tactics meaningful are often abandoned in HCI practice. This phenomenon not only characterizes the inclusion of art in HCI design practice, but appears to be part of a larger trend in HCI to depoliticize design, i.e. to shift focus from an exploration of political and social issues relevant to interaction to the generation of reliable methods and products.

In this, the uptake of Situationism follows in the footsteps of the transformation of Scandinavian participatory design (PD) into user-centered design, as documented by Asaro [8]. PD's original motivations were empowering workers in the process of democratizing the workplace and, at the same time, explicitly addressing the dehumanizing effects of increased technology presence in the workplace. Over the years, as participatory design become popular outside of Scandinavia and was incorporated in commercial system design, it was gradually transformed into a design approach that incorporates public dialogue and involves users in the design process. While user-centered design is still a useful and in some ways democratic approach, it has lost a substantial amount of the political framing that motivated PD. In other words, the view of technology as a tool to achieve political agency was replaced by the view of technology as a commercial product, while the goal of empowering the workers had been reduced to involving the users in the design process in order to understand their work practices, to gather requirements for the designed systems, testing and evaluating prototypes, etc.

One way to think about this kind of transformation is as removing politically charged aspects of a design approach in order to focus on its core intellectual or utilitarian possibilities. But, as Asaro discusses, it is important to recognize that the apparent depoliticization of PD did not result in an apolitical approach to design. To the contrary, the position that the political aspects of PD should be removed is itself a political stance, one that values the efficient production of broadly acceptable commercial software over reflection on complex power dynamics between business, workers, and customers. In this sense, PD was not depoliticized, but rather, altered to fit a different political agenda.

Similarly, as we have shown, Situationist tactics are divorced from their activist component, in what can be perceived to be an attempt to achieve political neutrality, but which actually represents the dominant political stance in HCI. This raises interesting questions about our discipline, which has traditionally focused on product design for the capitalist market. Is the tacit incorporation of capitalist ideology central to HCI or is it simply an unnoticed side effect of functioning in a predominantly capitalist society? What are the consequences for the technology we design and, ultimately, for the society we design for? Should political diversity be encouraged and could it lead to both scientific and social progress? We believe these questions can provide an opportunity for our community to discuss, imagine and crystallize its long term goals and research agenda. At the same time, they may allow us to better capitalize on the potential HCI holds as a site at which political, critical, and ideological questions about the role of technology in our culture can be raised and answered through design.

\section{ACKNOWLEDGMENTS}

The SIA project was developed in collaboration with Pavel Dmitriev. We are grateful to the organizers and participants in alt.chi for their feedback on earlier versions of this paper. This work was supported in part by NSF awards IIS-0238132 and IIS0534445

\section{REFERENCES}

[1] Adbusters. http://www.adbusters.org

[2] Asaro, P. 2000. Transforming society by transforming technology: the science and politics of participatory design. Accounting, Management and Information Technologies 10 (2000), 257-290.

[3] Ball, E. 1987. The Great Sideshow of the Situationist International. Yale French Studies, No. 73, Everyday Life. pp. 21-37. 
[4] Blythe, M. 2004. Pastiche scenarios. interactions 11, 5 (Sep. 2004), 51-53.

[5] Boehner, K., Vertesi, J., Sengers, P.,and Dourish, P. How HCI Interprets the Probes. In Proc. CHI 2007, ACM Press (2007), 1077-1086.

[6] Chang, M. and Goodman, E. FIASCO: Game Interface for Location-Based Play. In DIS2004, ACM Press (2004), 329332.

[7] Debord, G. Introduction to a Critique of Urban Geography. Les Levres Nues. \#6, 1955. http://library.nothingness.org/articles/SI/en/display/2

[8] Dourish, P. Implications for design. In Proc. CHI 2006. ACM Press (2006), 541-550.

[9] Dunning, A., Woodrow, P. and Hollenberg, M. Body degree zero. In MULTIMEDIA2005, ACM Press (2005), 10711072.

[10] Gemeinboeck, P., Tanaka, A., and Dong, A. Instant Archaeologies: Digital Lenses to Probe and Perforate the Urban Fabric. In MM'06, ACM Press (2006), 279-286.

[11] Gaver, W. W., Beaver, J. and Benford, S. Ambiguity as a Resource for Design. In Proc. CHI 2003. ACM Press (2003), 233-240.

[12] Gaver, W. W., Boucher, A., Pennington, S., and Walker, B. 2004. Cultural probes and the value of uncertainty. interactions 11, 5 (Sep. 2004), 53-56.

[13] Gaver, W. W., and Dunne, A. Projected Realities. In Proc. CHI 1999. ACM Press (1999), 600-607.
[14] Gaver, W. W.., Dunne, T., and Pacenti, E. 1999. Cultural probes. interactions 6, 1 (Jan. 1999), 21-29.

[15] Gaver, W.W., Hooker, B., and Dunne, A. (2001). The Presence Project. London: Royal College of Art.

[16] Gaye, L., Maze, R. and Holmquist L. E. Sonic City: The Urban Environment as a Musical Interface. In Proc. NIME03, ACM Press (2003), 109-332.

[17] Home, S. ed. What is Situationism? A Reader. AK Press, San Francisco, CA, USA, 1996.

[18] Höök, K., Sengers, P. and Andersson, G. (2003) Sense and Sensibility: Evaluation and Interactive Art. In Proc. CHI 2003, 241-248.

[19] McCarthy, J. and Wright, P. 2004 Technology As Experience. The MIT Press.

[20] Paulos, E. and Goodman, E. The familiar stranger: anxiety, comfort, and play in public spaces. In Proc. CHI 2004. ACM Press (2004), 223-230.

[21] Wright, P., McCarthy, J. and Marsh, T. (2000). From Usability to User Experience. Computers and Fun 3, York. Also appears in Interfaces, (46) 4-5, Spring (2001).

[22] Wyche, S., Sengers, P., and Grinter, R.E.. "Historical Analysis: Using the Past to Design the Future." In Proc. Ubiquitous Computing (Ubicomp) 2006, pp 35-51. 